\title{
A CFD Investigation of the Effects of Fuel Split Fraction on Advanced Low Temperature Combustion: Comparing a Primary Reference Fuel Blend and Ethanol
}

\author{
Mozhgan Rahimi Boldaji , Aimilios Sofianopoulos, Sotirios Mamalis and Benjamin Lawler \\ Department of Mechanical Engineering, Stony Brook University, Stony Brook, NY, United States
}

OPEN ACCESS

Edited by:

Evangelos G. Giakoumis, National Technical University of Athens, Greece

Reviewed by:

Liming Cai,

RWTH Aachen Universität, Germany

Derek Splitter,

Oak Ridge National Laboratory (DOE),

United States

Ming Jia,

Dalian University of Technology (DUT),

China

*Correspondence:

Mozhgan Rahimi Boldaji mozhgan.rahimiboldaji@ stonybrook.edu

Specialty section:

This article was submitted to Engine and Automotive Engineering, a section of the journal

Frontiers in Mechanical Engineering

Received: 01 March 2018 Accepted: 12 June 2018

Published: 06 July 2018

Citation:

Rahimi Boldaji M, Sofianopoulos A, Mamalis S and Lawler B (2018) A CFD Investigation of the Effects of Fuel Split

Fraction on Advanced Low

Temperature Combustion: Comparing a Primary Reference Fuel Blend and

Ethanol. Front. Mech. Eng. 4:6.

doi: 10.3389/fmech.2018.00006
There is continuously growing interest in renewable biofuels for combustion engines to help reduce transportation energy consumption. In the present work, ethanol and a Primary Reference Fuel (PRF) were studied in an advanced LTC concept using CFD. A split injection strategy was used where the majority of the fuel was injected early during the intake stroke to create a well-mixed charge, while a portion of the charge was direct injected closer to ignition to induce forced thermal and equivalence ratio stratification in a strategy similar to partial fuel stratification (PFS). This way, the combustion process in LTC can be better controlled by staggering the autoignition process through mixture stratification. The unique characteristics of ethanol, such as its high latent heat of vaporization and reduced $\phi$-sensitivity, result in unique features for a PFS-style advanced LTC mode, explored in this paper. A 3D CFD model with detailed chemistry was implemented in CONVERGE. The results showed that for both ethanol and PRF fuels, a split direct injection strategy lowers the peak heat release rate and elongates the combustion process compared to a single early direct injection due to the increased stratification. However, this effect was more pronounced for ethanol compared to PRF90 due to its higher latent heat of vaporization and reduced $\phi$-sensitivity. For a 60-40\% split injection, the burn duration increased by $118 \%$ for ethanol and $91.6 \%$ for PRF90. The temperature, equivalence ratio, and $\mathrm{OH}$ mass fraction distributions illustrated that ethanol is primarily temperature-sensitive, while PRF90 shows a degree of $\phi$-sensitivity in conjunction with temperature-sensitivity. The split direct injection of fuel creates an equivalence ratio and temperature distribution that are coupled due to the latent heat of vaporization of the fuel. For the PRF, these two effects are competing; whereas for the ethanol, the autoignition event is dictated by the thermal gradients since the fuel has a higher latent heat of vaporization and is not as $\phi$-sensitive. Therefore, a PFS-style injection strategy is able to elongate the heat release rates more significantly with ethanol compared to a PRF.

Keywords: advanced combustion, LTC, heat release, thermal stratification, equivalence ratio stratification, partial fuel stratification 


\section{INTRODUCTION}

Homogenous Charge Compression Ignition (HCCI) is a form of combustion that is based on autoignition of a lean and homogenous mixture (Onishi et al., 1979; Najt and Foster, 1983). HCCI combustion has been a topic of interest of many researchers because HCCI can operate on various type of fuels, offers very high efficiencies which are comparable to those of diesel engines, and produces very low amounts of $\mathrm{NO}_{\mathrm{X}}$ and soot emissions. HCCI is therefore of great interest for future combustion engines; however, HCCI suffers from some limitations that need to be addressed before commercialization. The load range in HCCI is limited by its misfire and variability on the low end and high pressure rise rates and noise on the high end. Due to the limited operating range of HCCI, other Low Temperature Combustion (LTC) modes have been proposed with the aim of increasing controllability over the combustion process and expanding the operating range. These LTC modes are based on the direct injection of fuel or water/water-fuel mixtures to create an equivalence ratio stratification and/or thermal stratification (Aoyama et al., 1996; Flynn et al., 2001; Aroonsrisopon et al., 2004; Kook and Bae, 2004; Tsolakis and Megaritis, 2005; Sjöberg and Dec, 2006; Berntsson and Denbratt, 2007; Kokjohn et al., 2011a,b; Sellnau et al., 2011; Splitter et al., 2011; Yang et al., 2011; Kodavasal et al., 2014, 2015; Kolodziej et al., 2015; Ansari et al., 2016; Johnson et al., 2017; Lawler et al., 2017b; Rahimi Boldaji et al., 2017, 2018a,b; Sofianopoulos et al., 2017, 2018; Shahsavan and Mack, 2018). Equivalence ratio stratification, achieved through direct fuel injection, can be used to control the combustion process by staggering the autoignition timing of various regions based on their local equivalence ratio. This is only applicable to fuels that are $\phi$-sensitive, meaning fuels whose autoignition timing is sensitive to their equivalence ratio, since some fuels are $\phi$-sensitive, and others are not. Thermal stratification occurs naturally due to turbulence and heat transfer between the charge and the relatively cool walls, or can be introduced through the heat of vaporization of a direct injected liquid (fuel, water, or water-fuel mixtures) to increase the temperature inhomogeneity. Due to the importance of thermal stratification on the combustion sequence in LTC, a unique postprocessing technique called the Thermal Stratification Analysis (TSA) was proposed for the quantification of the degree of thermal stratification from experimental data (Lawler et al., 2012, 2014a,b, 2017a). In either case, (equivalence ratio or thermal) stratification reduces the peak heat release rates by staggering the ignition process of various regions, resulting in increased controllability over the combustion process.

\footnotetext{
Abbreviations: aTDC, after Top Dead Center; CAD, Crank Angle Degrees; CFD, Computational Fluid Dynamics; CO, Carbon Monoxide; DI, Direct Injection; EVC, Exhaust Valve Closing; GCI, Gasoline Compression Ignition; GDCI, Gasoline Direct Injection Compression Ignition; HCCI, Homogeneous Charge Compression Ignition; HRR, Heat Release Rate; IMEP, Indicated Mean Effective Pressure; IVC, Intake Valve Closing; IVO, Intake Valve Opening; LTC, Low Temperature Combustion; NOx, Oxides of Nitrogen (NO or $\mathrm{NO}_{2}$ ); PCCI, Premixed Charge Compression Ignition; PFS, Partial Fuel Stratification; PRF, Primary Reference Fuel; RCCI, Reactivity Controlled Compression Ignition; TDC, Top Dead Center; TSCI, Thermally Stratified Compression Ignition.
}

Thermally Stratified Compression Ignition (TSCI) (Lawler et al., 2017b; Rahimi Boldaji et al., 2017, 2018b) is a relatively new LTC mode which focuses on the controlling the thermal stratification within the cylinder as a means to control the combustion process. TSCI intentionally stratifies the temperature distribution throughout the cylinder beyond what would occur naturally to facilitate control over the heat release process. TSCI is enabled using either direct water injection or direct injection of water-fuel mixtures. The latent heat of vaporization of water droplets absorbs the energy from the surrounding mixture and reduces the temperature of these regions. This way, TSCI can control both the average and local temperatures, and can therefore provide control over the start and rate of combustion simultaneously. TSCI enabled by water injection was shown experimentally to extend the load range from 2.3 to 3.6 bar gross indicated mean effective pressure (IMEP) in HCCI to 2.3-8.4 bar in TSCI, which is a $350 \%$ expansion of the load range (Lawler et al., 2017b).

Premixed Charge Compression Ignition (PCCI) (Aoyama et al., 1996; Flynn et al., 2001; Kook and Bae, 2004; Tsolakis and Megaritis, 2005) is an LTC modes that takes advantage of equivalence ratio stratification. PCCI uses a diesel-like fuel with an equivalence ratio stratification to increase the controllability over the combustion process compared to HCCI while producing less pollutant emissions (soot and NOx) compared to conventional diesel combustion. Gasoline Compression Ignition (GCI) (Kodavasal et al., 2014, 2015; Kolodziej et al., 2015) and Gasoline Direct Injection Compression Ignition (GDCI) (Sellnau et al., 2011) are also two advanced combustion modes which provide control over the combustion process by manipulating the reactivity of mixture through the direct injection of gasoline to create an equivalence ratio stratification. Reactivity Controlled Compression Ignition (RCCI) (Kokjohn et al., 2011a,b; Splitter et al., 2011; Ansari et al., 2016) is another equivalence ratio stratification-driven LTC mode which uses more than one fuel. The low reactivity fuel, for example gasoline, is port fuel injected or direct injected very early to create a homogenous mixture with the incoming air, while the second, highly reactive fuel, for example diesel, is direct injected during the compression stroke to create reactivity gradients due to the fuel property inhomogeneities, as well as the equivalence ratio stratification.

Sjöberg and Dec (2006) proposed another stratificationcontrolled combustion mode called Partial Fuel Stratification (PFS). PFS is able to decrease the pressure rise rates by staggering the combustion event, thereby expanding the high-load limit of LTC. They showed that PFS is more effective when it is combined with two-stage ignition fuels rather than a single-stage ignition fuel (Sjöberg and Dec, 2006). PFS requires the ignition timing of fuel to be sensitive to the local equivalence ratio $(\phi)$ (Sjöberg and Dec, 2006; Yang et al., 2011), which they have termed " $\phi$ sensitivity." Fuels with low temperature heat release (i.e., twostage ignition fuels like diesel) have shown the $\phi$-sensitivity characteristics required for PFS, while some single-stage fuels, such as ethanol, have little or no $\phi$-sensitivity. The effect of engine speed, intake temperature, and fuel composition on the performance of two-stage ignition fuels with PFS have been studied in the literature (Yang et al., 2011). PFS was also tested in a 
boosted HCCI engine fueled by gasoline (Dec et al., 2011). While PFS is relatively ineffective for gasoline under naturally aspirated conditions, it becomes very successful at reducing the pressure rise rate when boosted because the $\phi$-sensitivity of gasoline has a pressure dependence. PFS was further studied in a boosted gasoline HCCI engine computationally (Wolk et al., 2015). It was found that under naturally aspirated conditions, the sequential autoignition of gasoline PFS starts with the premixed portion of the mixture which is leaner than the regions with higher $\phi$; whereas for boosted conditions, the autoignition starts with the richer regions.

Sjöberg and Dec have also used ethanol with a PFS-style split injection strategy to increase the controllability (Sjoberg and Dec, 2011). Using direct injection of ethanol, which has a high latent heat of vaporization, during the late compression stroke results in an increased thermal stratification throughout the cylinder. They varied the amount of ethanol injected in the first and second injection, as well as injection timing, and they found that injecting $30-40 \%$ of the ethanol at $-80^{\circ}$ Crank Angle Degree (CAD) after Top Dead Center (aTDC) results in a very smooth heat release rate. The current work expands on the previous study of split injection strategies with ethanol for vaporization-induced thermal stratification to study the effect of ethanol injection on thermal stratification and combustion in more detail using computational tools.

Ethanol is a valuable source of energy as an alternative to fossil fuels and is fairly widespread throughout the world. The diverse set of sources of ethanol, along with its lower associated carbon dioxide $\left(\mathrm{CO}_{2}\right)$ emissions, adds to the greater motivation of the present work. In the current study, ethanol and PRF90 are early Direct Injected (DI) and split injected during the early intake and late compression strokes at different fractions to study the effect of fuel split fraction on the combustion process in LTC. The distinct behavior of the two fuels is compared.

\section{CFD MODEL COMPUTATIONAL FRAMEWORK}

The engine modeled in this work was a production 4-cylinder, 2.0L engine manufactured by General Motors (type LNF). This engine was tested experimentally (Lawler et al., 2017b) for both HCCI and TSCI modes. Some modifications were made to enable HCCI and TSCI including NVO camshafts to allow a high level of residual gas trapping and facilitate the autoignition process. For a detailed description of these modifications, please refer to Lawler et al. (2017b). Figure 1 shows the Computational Fluid Dynamics (CFD) model geometry which was built in CONVERGE (Richards et al., 2014). CONVERGE is a CFD code with the ability to perform 3-D flow simulations as well as turbulence, combustion, and spray modeling. As shown in Figure 1, this engine has a side-mounted direct injector which is used to inject the fuel directly into the combustion chamber. Table 1 provides a summary of the engine specifications.

In this study, two different mechanisms were used to simulate a Primary Reference Fuel (PRF) blend and ethanol. For the PRF blend, a mechanism presented by Liu et al. (2012), which

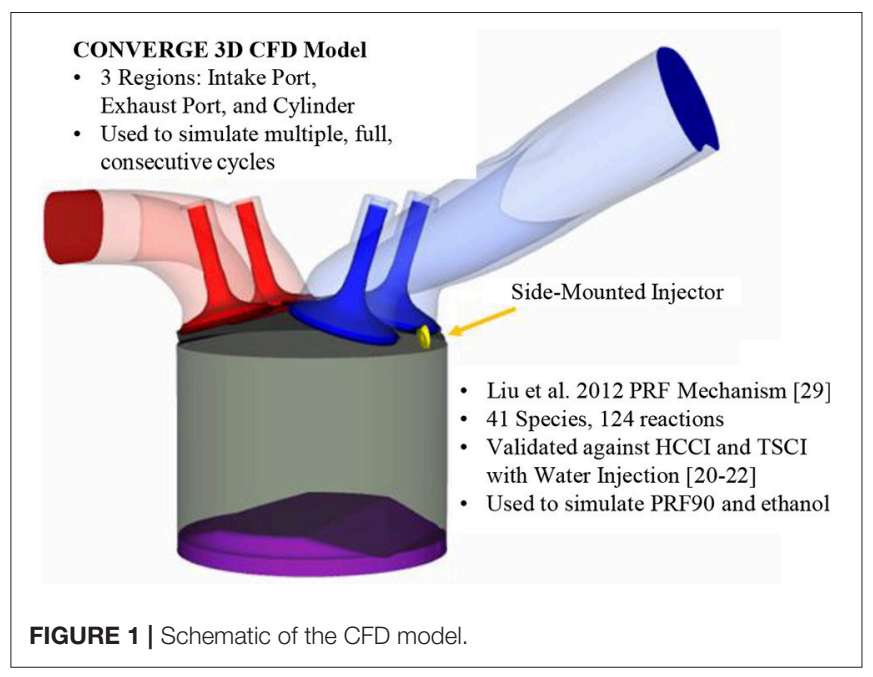

TABLE 1 | Engine specifications.

\begin{tabular}{lc}
\hline Bore & $86 \mathrm{~mm}$ \\
Stroke & $86 \mathrm{~mm}$ \\
Connecting rod length & $145.5 \mathrm{~mm}$ \\
Compression ratio & $12.5: 1$ \\
Valve timings & $\mathrm{IVO}-276^{\circ}, \mathrm{IVC}-150^{\circ}, \mathrm{EVO} 148^{\circ}, \mathrm{EVC} 274^{\circ}$ \\
Engine speed & $2,000 \mathrm{rpm}$ \\
Fuel & $\mathrm{PRF} 90$ and Ethanol \\
\hline
\end{tabular}

consists of 41 species and 124 reactions, was utilized to simulate the PRF. This mechanism was validated extensively against experimental data, such as shock tube, jet-stirred reactor, and flow reactor results for HCCI-relevant conditions, as well as HCCI engine data (Liu et al., 2012). Kodavasal and Kolodziej et al. (Kodavasal et al., 2015) have shown that this mechanism has relatively small differences compared to a larger and more detailed mechanism (Mehl et al., 2011), while significantly reducing the computational time. In this study, a blend of $10 \% \mathrm{n}$ heptane and 90\% isooctane (PRF90) was chosen as a surrogate for gasoline. Additionally, ethanol was simulated using an ethanol mechanism from Lawrence Livermore National Laboratory (Marinov, 1999). This mechanism contains of 56 chemical species and 351 reactions. This mechanism was validated against multiple experimental data sets including laminar flame speed measurements in a constant volume bomb and counter-flow twin flame ignition delay measurements from shock tube data, and species concentrations from jet-stirred and flow reactors. Good agreement was achieved between the experimental and modeling results of this mechanism (Marinov, 1999).

A base orthogonal cut-cell grid of $4 \mathrm{~mm}$ is employed in the intake and exhaust ports, while the grid size is reducing to $1 \mathrm{~mm}$ throughout the entire combustion chamber, $0.5 \mathrm{~mm}$ around the intake and exhaust valves, and $0.25 \mathrm{~mm}$ around the injector. Also, adaptive mesh refinement (AMR) is used in the model to refine the mesh based on the sub-grid values of temperature, velocity, $\mathrm{HO}_{2}, \mathrm{OH}, \mathrm{CO}$, and $\mathrm{O}_{2}$ mass fraction. 
The SAGE chemistry solver (Senecal et al., 2003) has been used for modeling the combustion chemistry in this work along with the multi-zone model of Babajimopoulos et al. (2005). Turbulence is modeled through the Reynolds-Averaged NavierStokes (RANS)-based renormalization group (RNG) k- $\varepsilon$ model (Yakhot and Orszag, 1986; Han and Reitz, 1995). The present study utilizes the Kelvin-Helmholtz and Rayleigh-Taylor (KHRT) hybrid model (Reitz and Bracco, 1986; Su et al., 1996; Beale and Reitz, 1999) for modeling atomization and breakup of the fuel droplets. The drop drag coefficient is calculated using the dynamic drop drag model of Liu et al. (1993). In addition to the aforementioned atomization and drop drag models, the No Time Counter (NTC) method of Schmidt and Rutland (2000) and the Chiang et al. (1992) correlation are included in this work to account for droplet collision and evaporation of droplets, respectively. Finally, a spray sub-model is employed to simulate the interaction between the spray and the engine walls (Richards et al., 2014). All of these models are adequately described and well-used in the literature.

\section{CFD MODEL VALIDATION}

Validation of the CFD model in this work is conducted using the pressure and heat release rate curves of previously collected experimental data (Lawler et al., 2017b). Simulations were performed for three consecutive cycles to improve the flow field development and predictions of residual gas fraction and residual temperature, resulting in more accurate CFD predictions. The validation case shown in this section is the result of the third simulated cycle. The first cycle was initialized according to the experimental data and adjusted slightly to achieve better agreement. The second and third cycles were initialized using the mapped results at the end of previous cycle. The slight adjustments are expected due to the uncertainty of some of the experimental data that are not directly measured, such as the internal residual gas fraction or bulk cylinder temperature. In addition to the adjustment to some of experimental data, a few of the default values of the sub-model constants were also changed slightly, which can be expected due to the inherit difference between the sub-models and physical processes. For instance, the intake temperature is usually adjusted in the CFD simulations to compensate for slight differences between the chemical kinetics mechanism and the actual kinetics in the experiment. Table 2 lists the initial and boundary conditions that were modified to account for the uncertainties. The CFD simulation result for HCCI combustion and the experimental HCCI data are shown in Figure 2. Figure 2 shows that the CFD data of HCCI agrees well with the experimental data. Therefore, the CFD model is able to simulate HCCI combustion accurately and capture the desired trends.

\section{RESULTS AND DISCUSSION}

CFD simulations were performed for PRF90 and ethanol to investigate the effects of fuel injection split fraction on combustion and evaluate the thermal sensitivity and $\phi$-sensitivity
TABLE 2 | Operating condition of the validated case.

\begin{tabular}{lcl}
\hline & Simulation & Experiment \\
\hline Wall temperature & $430 \mathrm{~K}$ & Not directly measured \\
Intake temperature & $373 \mathrm{~K}$ & $403 \mathrm{~K}$ \\
Equivalence ratio & 0.74 & 0.74 \\
Residual rate & 0.45 & 0.41 \\
IMEPg & $3.7 \mathrm{bar}$ & $3.7 \mathrm{bar}$ \\
Engine speed & $2,000 \mathrm{rpm}$ & $2,000 \mathrm{rpm}$
\end{tabular}

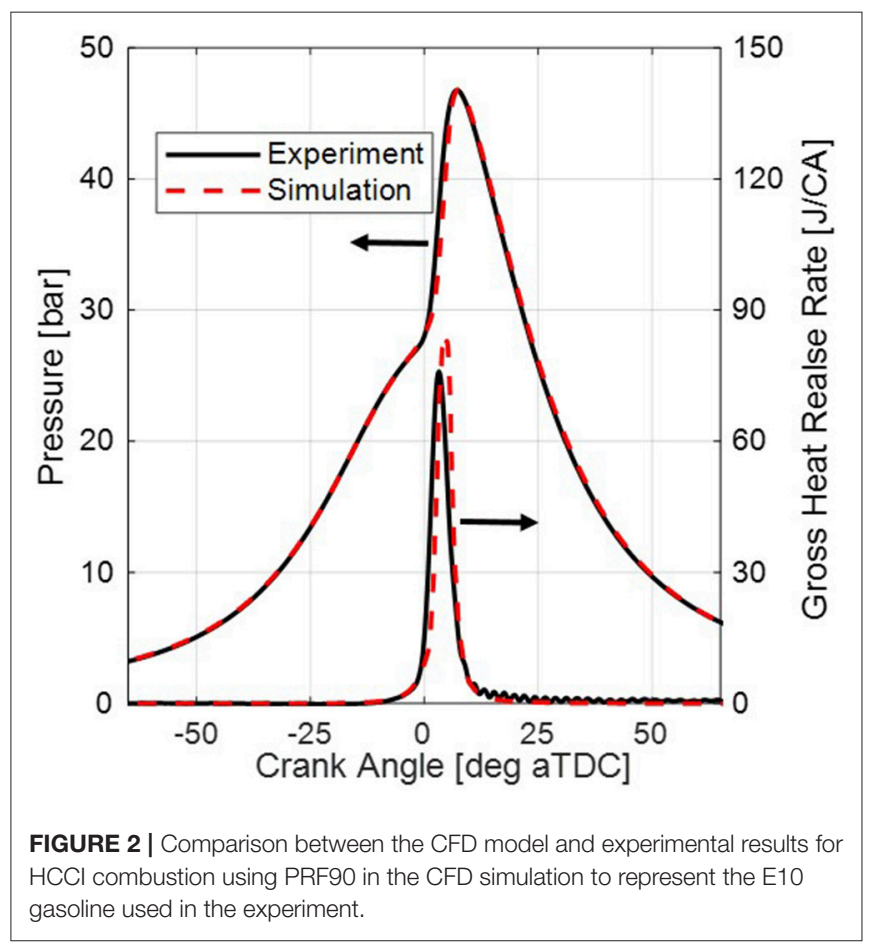

of each of the fuels. The total energy input of the system was kept constant for both fuels by adjusting their total injected mass based on the lower heating value of each fuel. The total injected mass of PRF90 and ethanol were 9.5 and $15.4 \mathrm{mg} /$ cycle, respectively. Two separate injections were employed. The first injection (the early injection) occurred at $-300^{\circ}$ aTDC to create a well-mixed charge and the second injection (the late injection) started at $-40^{\circ}$ aTDC to establish the stratification within the cylinder. The amount of mass in each injection was varied from $100-0 \%$ (i.e., $100 \%$ in the first injection and $0 \%$ in the second injection) to $80-20 \%$, and finally $60-40 \%$. The injection pressures were kept at 160 bar throughout the paper, while only their durations changed to account for the various masses. Additionally, the intake temperature was adjusted for the early Direct Injection (DI) ethanol and PRF cases such that they have the same combustion phasing. From this point onward, the intake temperature was kept constant for the split DI cases for each fuel. All other operating parameters including the engine speed and injector specifications were kept constant. The specifications of the injector are listed in Table 3. 


\section{Effect of Ethanol vs. PRF Fuel Split Fraction on Combustion}

Ethanol and PRF90 fuels were split direct injected into the combustion chamber during the intake stroke and late compression stroke to create a partially stratified combustion mode. The $80-20$ and $60-40 \%$ split fractions, as well as the $100-$ $0 \%$ (Early DI) reference case, were tested for each fuel. Figure 3 shows the pressure trace for the different injection strategies for both PRF90 and ethanol. As shown in Figure 3, increasing the fuel fraction of the second injection reduces the peak pressure for both fuels. Injecting more fuel in the second injection, which occurs late in the compression stroke $\left(-40^{\circ} \mathrm{CAD}\right.$ aTDC), results in more thermal and equivalence ratio stratifications. The increased thermal and equivalence ratio stratifications stagger the autoignition timing of various regions and reduce the peak pressure.

Figure 4 shows the effect of fuel split fraction on the gross heat release rate. As can be seen from this figure, injecting more fuel in the second injection decreases the peak heat release rate. This is because injecting more fuel in the second injection increases the stratification of mixture's temperature and equivalence ratio

TABLE 3 | Injector specifications.

\begin{tabular}{ll}
\hline Number of nozzle holes & 6 \\
Injection spray type & Solid cone spray \\
Nozzle diameter & $0.2 \mathrm{~mm}$ \\
Spray cone angle & $26^{\circ}$ \\
Injection duration & $2.8-10.5$ CAD \\
Stat of injection & $-300^{\circ}$ aTDC \& $-40^{\circ}$ aTDC \\
Injection pressure & 160 bar \\
Injector mounting type & Side-mounted
\end{tabular}

immediately before ignition (which will be discussed in more detail later). The stratified mixtures have a more staggered combustion event which results in a lower peak heat release rate. Figure 4 also shows that ethanol has a stronger effect on lowering the heat release rate compared to PRF90. Ethanol has a higher heat of vaporization than PRF90 ( $~ 2.7$ time higher) meaning that ethanol absorbs more energy from the mixture compared to PRF90, which results in an intensified evaporative cooling effect. Additionally, the lower energy density of ethanol indirectly results in more evaporative cooling because more liquid is injected for the ethanol. The stronger vaporization cooling effect of ethanol increases the thermal stratification in the cylinder and results in reduced heat release rates. This fact can be seen from Figure 4 by comparing the peak heat release rates. The peak heat release rates for the Early DI, 80-20\% split DI, and $60-40 \%$ split DI cases are 89,74 , and 58 J/CA, respectively. The same values for ethanol are 98, 76, and $42 \mathrm{~J} / \mathrm{CA}$, respectively. For PRF90, the peak heat release rate is only reduced from 89 to 58 $\mathrm{J} / \mathrm{CA}$ (a reduction of 35\%), whereas the peak heat release rate is reduced from 98 to $42 \mathrm{~J} / \mathrm{CA}$ for ethanol (a reduction of 57\%). This difference will be explored in more detail later in this paper.

The 10-90\% burn durations are illustrated in Figure 5. Overall, ethanol has a shorter burn duration compared to PRF90 for any of the split injection mass fractions. This is expected since ethanol exhibits pure single-stage heat release, whereas PRF90 is a blend of isooctane and n-heptane which causes the heat release process to occur over a wider range of temperatures and therefore crank angles. More importantly, it can be seen from Figure 5 that increasing the fraction of fuel in the later injection increases the burn duration for both fuels. The longer burn durations for the cases with a higher fuel fraction in the second injection is due to the enhanced thermal and equivalence ratio stratifications. The burn duration for PRF90 increases from $7.2^{\circ} \mathrm{CAD}$ for the
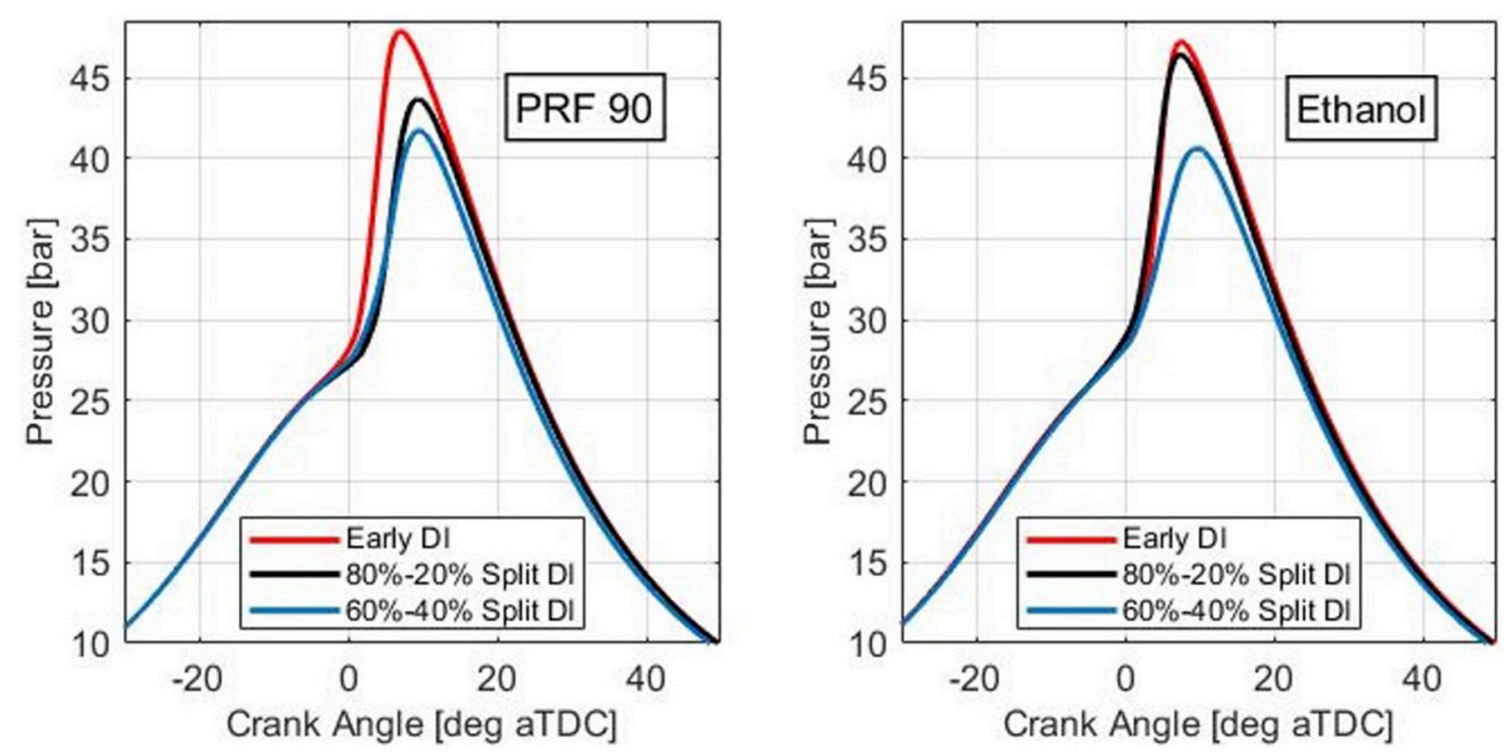

FIGURE 3 | Effect of fuel injection split fraction on the cylinder pressure of LTC for PRF90 and ethanol. Increasing the fuel fraction in the second injection (late injection) decreases the peak pressure. 

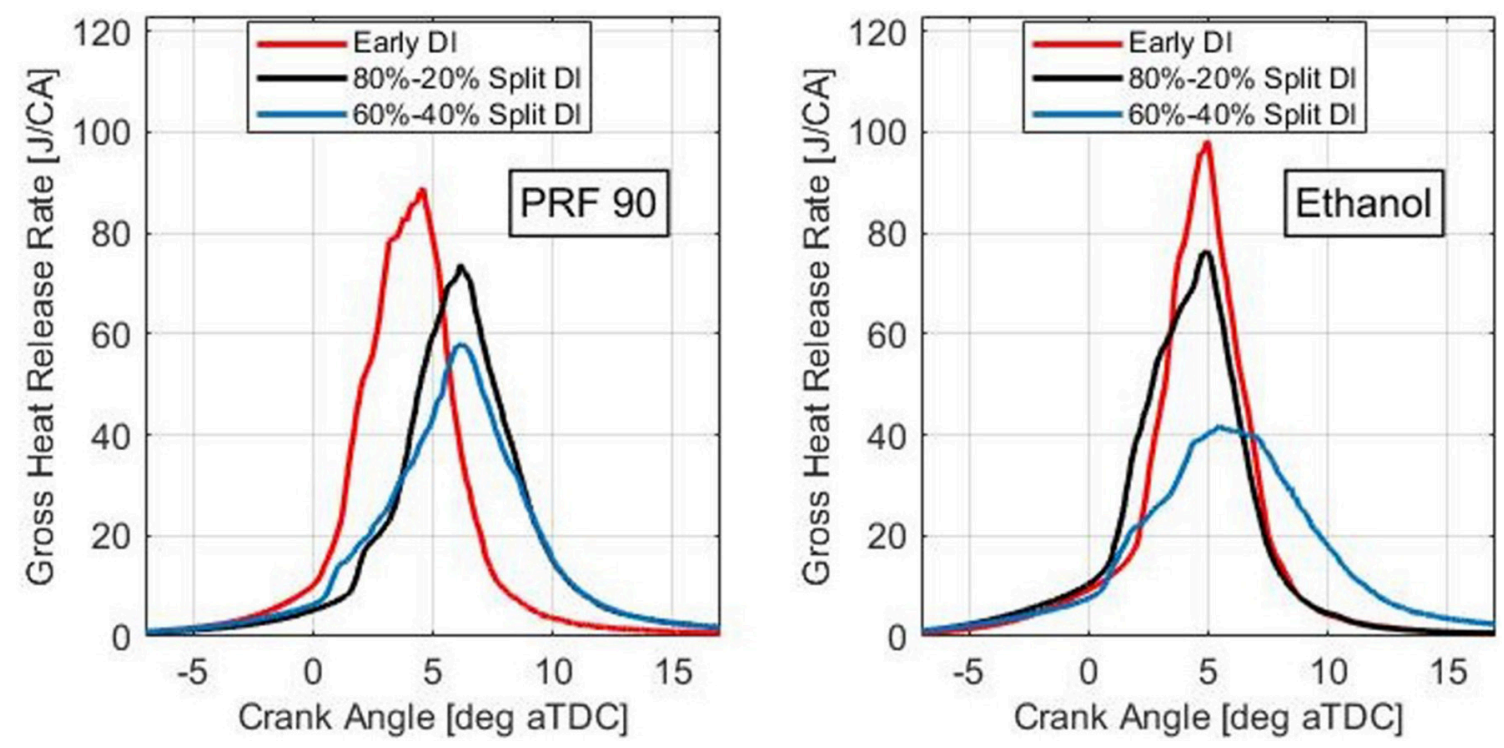

FIGURE 4 | Effect of fuel injection split fraction on Heat Release Rate (HRR) of LTC for PRF90 and ethanol. Increasing the fuel fraction in the second injection (late injection) decreases the peak HRR. Also, ethanol has a more prounced effect on lowering the peak HRR compare to PRF90.

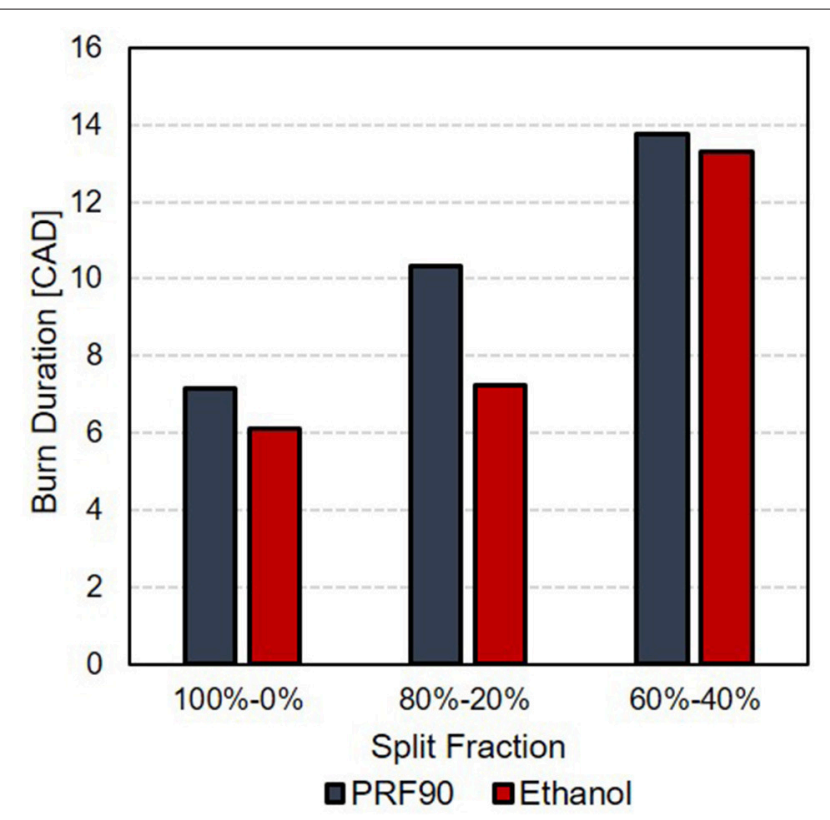

FIGURE 5 | Effect of fuel injection split fraction on the burn duration for PRF90 vs. ethanol. Injecting higher fuel fractions in the late injection elongates the burn duration due to the increased mixture stratifcation. For ethanol, the burn duratin increases more than PRF90.

$100-0 \%$ case to $10.3^{\circ}$ and $13.7^{\circ}$ CAD for the $80-20$ and $60-$ $40 \%$ cases, respectively. For ethanol, the burn duration expands from $6.1^{\circ} \mathrm{CAD}$ for the $100-0 \%$ case to $7.3^{\circ} \mathrm{CAD}$ and $13.3^{\circ} \mathrm{CAD}$ for the $80-20$ and $60-40 \%$ cases, respectively. Additionally, it is noticeable from this plot that the level of increase of ethanol's burn duration with the split injection strategy is greater than the level of increase of the PRF90's burn duration. The burn duration of the ethanol and the PRF90 increases by 118 and $91.6 \%$, respectively, for the $60-40 \%$ split DI case compared to the early DI case. There are several reasons for the difference between ethanol and the PRF, including the higher latent heat of vaporization of the ethanol. These reasons will be explained in more detail in the following section.

To better understand how the direct fuel injection event reduces the peak heat release rate and elongates the burn duration of advanced LTC, the equivalence ratio and temperature distributions are analyzed in the following section. Also, these distributions help investigate how the combustion event of ethanol and PRF90 (portrayed by the $\mathrm{OH}$ mass fraction) relates to the temperature and equivalence ratio of the mixture.

\section{Thermal Sensitivity and $\phi$-Sensitivity of Ethanol vs. PRF90}

Figure 7 shows the vertical and horizontal cut-planes of temperature, equivalence ratio, and $\mathrm{OH}$ mass fraction distributions for the early DI and $60-40 \%$ split DI cases for ethanol. The locations of these cut-planes are shown in Figure 6. The $\mathrm{OH}$ mass fraction is shown at $-4^{\circ} \mathrm{CAD}$ to indicate the locations where combustion is occurring at a timing toward the beginning of the global heat release process. The temperature and equivalence ratio distributions are captured at $-12^{\circ} \mathrm{CAD}$, which is a timing before the onset of combustion to avoid any changes to these distributions due to combustion. The cut-planes in Figure 7 show that the temperature and equivalence ratio of the early DI case exhibit a nearly uniform distribution over the cylinder with only slight changes in temperature or equivalence ratio. As a result, the $\mathrm{OH}$ mass fraction distribution is relatively homogeneous, meaning that the combustion happens around the same time over the majority of the combustion chamber. 

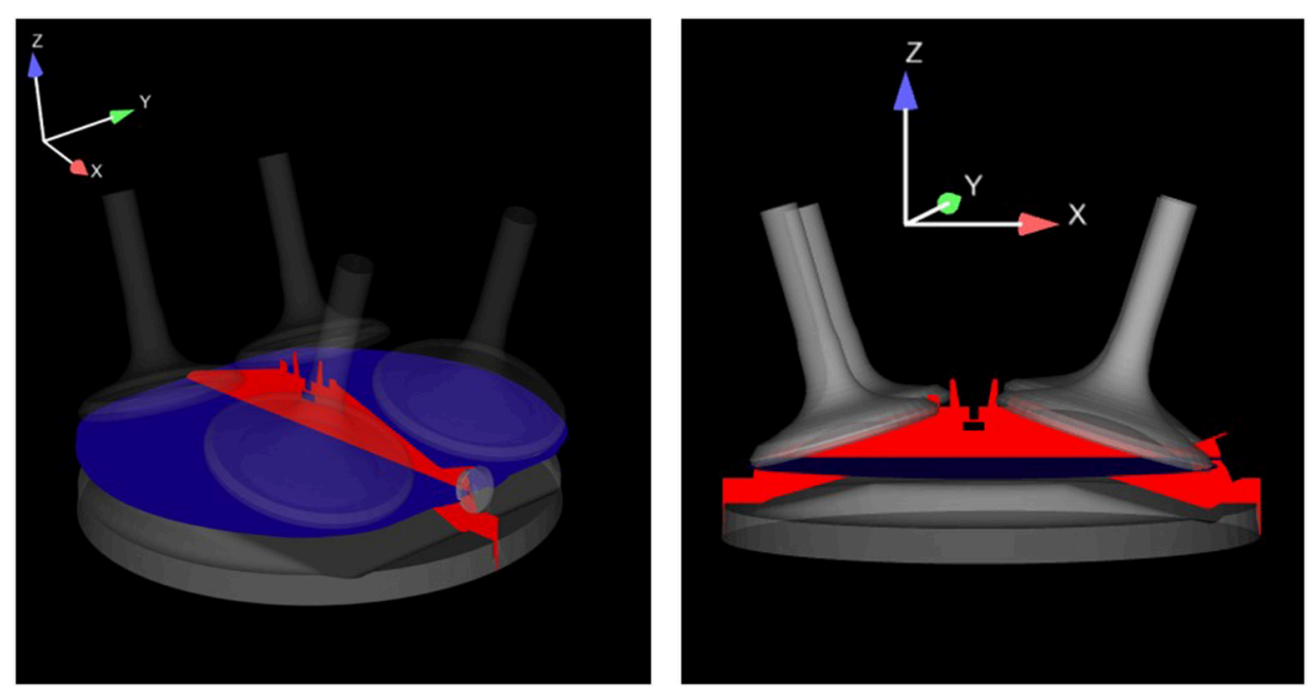

FIGURE 6 | Location of horizontal (blue) and vertical (red) cut-planes selected for capturing the temperature and equivalence ratio distributions.

However, for the $60-40 \%$ split DI case, the temperature and equivalence ratio distributions becomes stratified. The regions that are unaffected by the spray are hotter and have a lower equivalence ratio; while the regions that are targeted by the spray are colder with a higher equivalence ratio. The reduced temperature of the regions targeted by the spray is due to the evaporative cooling effect of the fuel droplets. It is important to note that the latent heat of vaporization of ethanol is significantly higher than other fuels, and since the energy density is lower, more mass needs to be injected to achieve a target load level. Therefore, the evaporative cooling effect when ethanol is direct injected is significantly larger than other fuels. This evaporative cooling effect increases the thermal stratification throughout the cylinder. Additionally, the direct injection of fuel creates an equivalence ratio stratification.

In general, in PFS, the thermal and equivalence ratio stratification are two factors that result in enhanced control over the combustion process by staggering the combustion event, reducing the peak heat release rate, and elongating the combustion duration. When using a direct injection of fuel, the thermal and equivalence ratio stratification are directly coupled (i.e., the richer regions are colder and the leaner regions are hotter). For all fuels, their autoignition timing is sensitive to their local temperature. However, only some fuels exhibit a sensitivity to the equivalence ratio and other fuels either exhibit no sensitivity to the local equivalence ratio, or a significantly reduced sensitivity (Sjöberg and Dec, 2006). Fuels whose autoignition timing is affected by their equivalence ratio are called $\phi$-sensitive.

According to Figure 7, the $\mathrm{OH}$ mass fraction diagram of the $60-40 \%$ split DI case for ethanol is very similar to the temperature distribution. The hotter regions, which are leaner, ignite first (e.g., region $\mathrm{B}$ ), while the colder and richer regions ignite last (e.g., region $\mathrm{A}$ ) which means that the combustion process is dictated primarily by the temperature and not the equivalence ratio. Therefore, combustion starts from the hot regions rather than the rich regions. This is in agreement with previous finding of Sjoberg and Dec (2011), where they showed that ethanol has little to no $\phi$ sensitivity. The fact that ethanol is not very sensitive to variation in equivalence ratio means that the local temperature governs the onset of ignition for ethanol and combustion progresses from the high temperature regions to the low temperature regions (i.e., low to high equivalence ratios). This could allow for slightly more time for mixing of the rich regions, which might result in less soot and CO emissions compared to fuels that autoignite from rich to lean regions. Factors like these need further exploration, but it is important to note that the combustion sequence (rich regions first and lean regions last, or alternatively, lean regions first and rich regions last) is different for different fuels and that the combustion sequence could have implications for emissions formation.

In addition to the ethanol, cut-plane distributions of temperature, equivalence ratio, and $\mathrm{OH}$ mass fraction are captured for PRF90 in Figure 8. Similar to the ethanol, the early DI case of PRF90 has a relatively homogenous temperature, equivalence ratio, and $\mathrm{OH}$ mass fraction distributions compared to the $60-40 \%$ split DI case. In the $60-40 \%$ split DI case, the regions that are targeted by the spray are richer and the regions unaffected by the spray are leaner. This results in a stratification of equivalence ratio. Additionally, the regions targeted by the spray are cooler than the regions unaffected by the spray due to the fuel droplet evaporation. This results in an increased degree of thermal stratification compared to the early DI case. The temperature distribution and the equivalence ratio distribution are directly coupled (and inversely related) since they were both induced by the spray (i.e., the lean regions are hotter, and the rich regions are cooler). Both of these factors, the equivalence ratio distribution and the temperature distribution, create a staggered combustion sequence for the PRF with a lower heat release rate and a longer burn duration, compared to the early DI case. More importantly, unlike ethanol, the combustion 


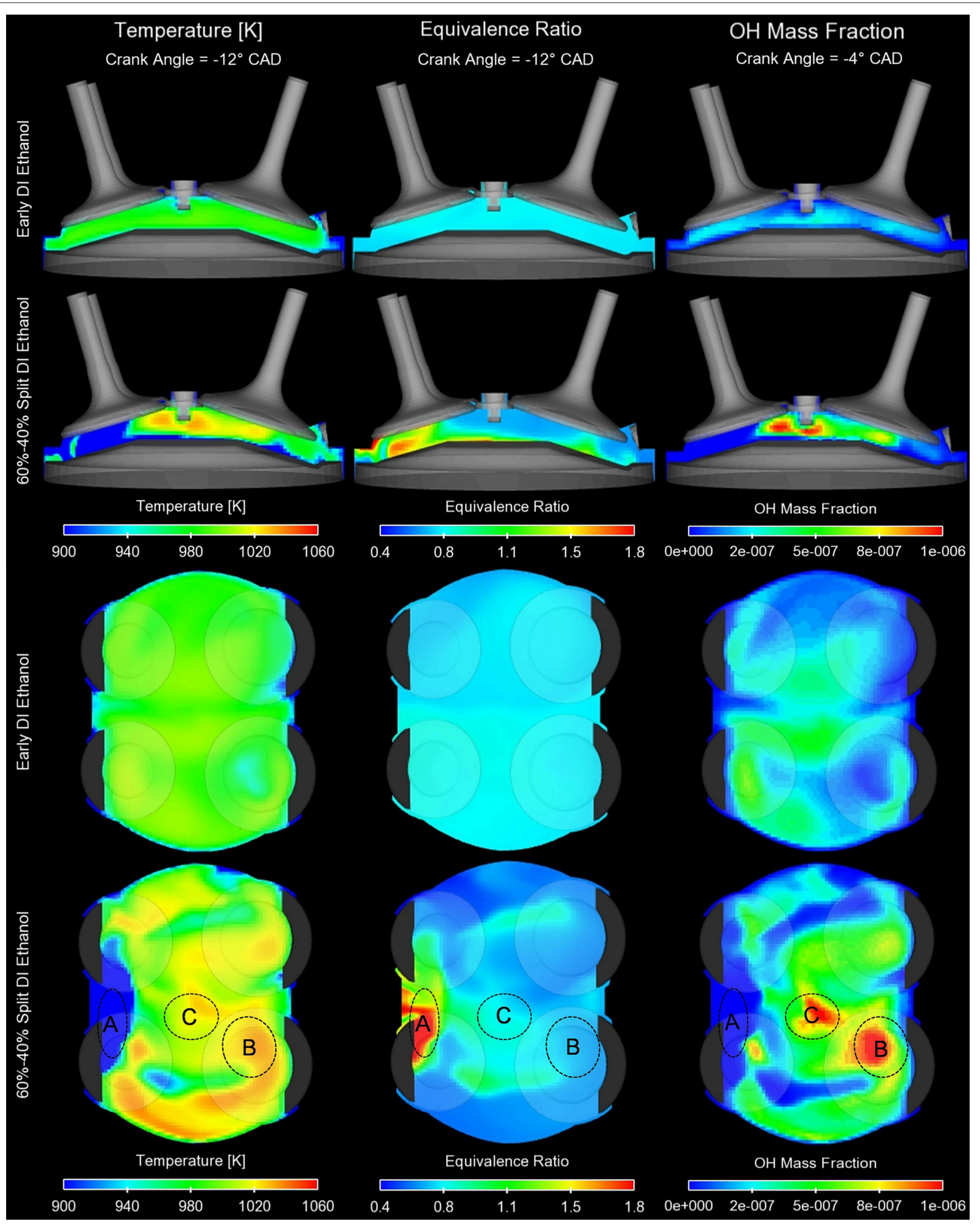

FIGURE 7 | Ethanol: Vertical and horizontal cut-planes of temperature, equivalence ratio, and OH mass fraction distributions for the early DI case and the 60-40\% split DI case. The temperature, equivalence ratio, and $\mathrm{OH}$ mass fraction distributions are fairly uniform for early $\mathrm{DI}$ case; while for the $60-40 \% \mathrm{DI}$ case, these distributions are stratified due to the second direct injection. Also, it is clear that the $\mathrm{OH}$ mass fraction distribution is governed by the temperature distribution and not the equivalence ratio distribution. 


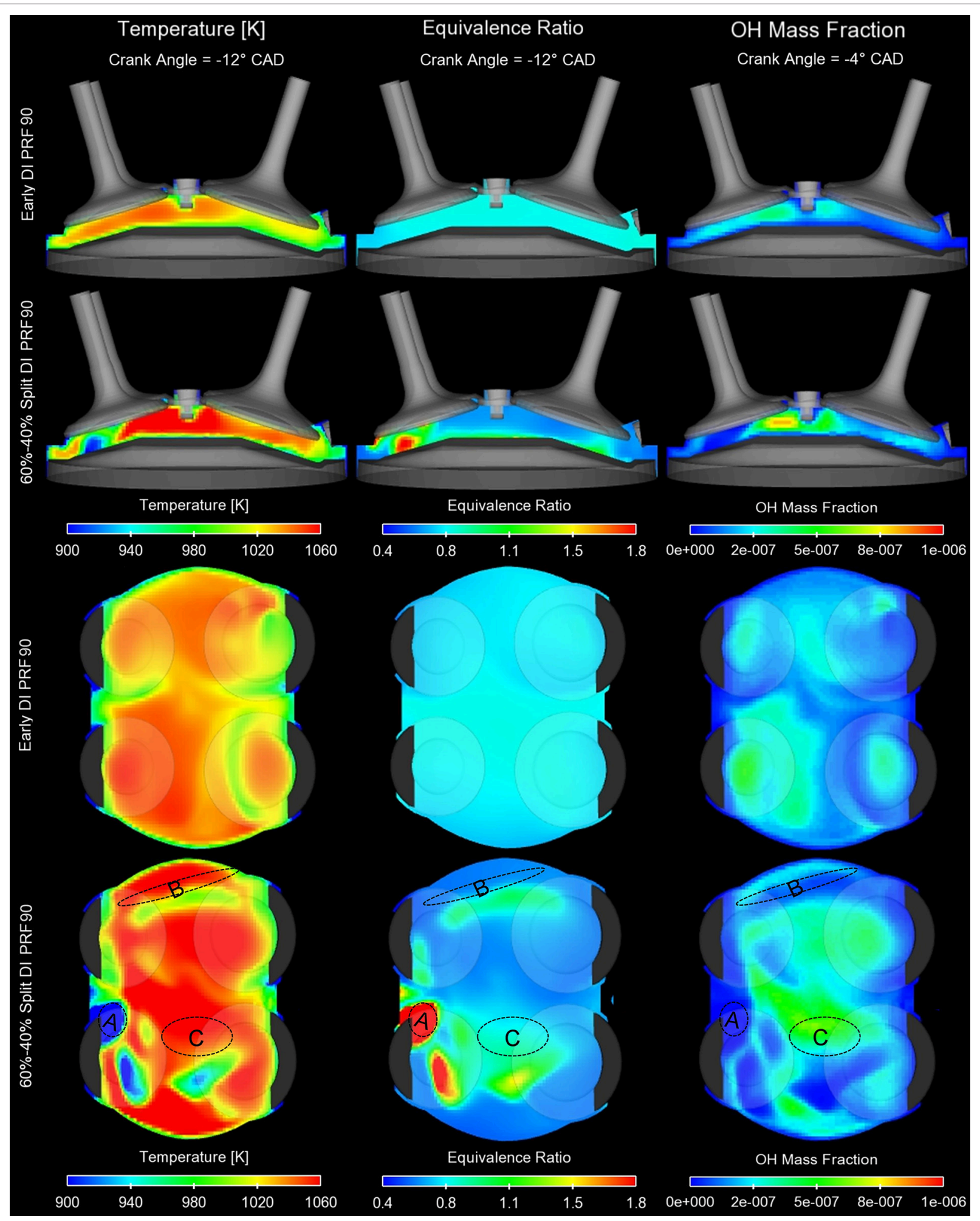

FIGURE 8 | PRF90: Vertical and horizontal cut-planes of temperature, equivalence ratio, and OH mass fraction distributions for the early DI and 60-40\% split DI cases. The temperature, equivalence ratio, and $\mathrm{OH}$ mass fraction distributions are fairly uniform for the early $\mathrm{DI}$ case; while for the $60-40 \%$ split $\mathrm{DI}$ case, these distributions are stratified due to the direct fuel injection. Also, it is clear that the $\mathrm{OH}$ mass fraction distribution is governed by both the temperature and the equivalence ratio distribution and they compete with each other to dictate the autoignition of PRF90. 
sequence of PRF90 is not exclusively dictated by the temperature distribution; instead, the combustion sequence depends on both the temperature and equivalence ratio distributions, with the temperature being the dominant factor at these conditions. This is better explained by examining the labeled regions in Figure 8 . In contrast to ethanol, region B is hot, but also lean, and therefore is not one of the early igniting regions (as indicated by the $\mathrm{OH}$ fraction). Instead, region $\mathrm{C}$ that is hot and intermediately rich is one of the first igniting regions. Region $\mathrm{A}$, which was directly targeted by the spray is therefore cold and very rich, has a near-zero $\mathrm{OH}$ concentration indicating that combustion reactions are not occurring in this region yet (which is similar to the richest regions targeted by the spray in the ethanol case shown in Figure 7). This shows that PRF90 is sensitive to both the local temperature and equivalence ratio ( $\phi$-sensitivity), and since these two distributions are directly coupled in the case of a direct fuel injection event, these two factors compete with each other for the PRF. The same was not true for the ethanol-the combustion sequence in the ethanol was primarily dictated by the temperature distribution and ethanol exhibits more evaporative cooling than other fuels. This explains the larger change in peak heat release rate for ethanol shown in Figure 4 or the burn duration shown in Figure 5. Previously, Dec et al. (Sjoberg and Dec, 2011; Yang et al., 2011; Wolk et al., 2015) found that gasoline and high PRF number fuels are not as $\phi$-sensitive at atmospheric intake pressure, but become much more $\phi$-sensitive at elevated pressure (i.e., boosted intake pressures). The results of this work are in agreement with the findings of Dec et al. (Sjoberg and Dec, 2011; Yang et al., 2011; Wolk et al., 2015) since the current simulations are at atmospheric pressure. Future studies of boosted conditions could shed light on how the combustion sequence changes for elevated pressures (i.e., determining the pressures at which the $\phi$-sensitivity begins to dominate the combustion sequence).

Altogether, the results of this work suggest that direct injection of ethanol is a good solution for controlling advanced LTC with a PFS-style injection strategy by pairing the high heat of vaporization with ethanol's reduced $\phi$-sensitivity. These factors results in better control over the heat release rate when ethanol is direct injected; whereas for PRF fuels (as a surrogate for gasoline), the heat release rates show a lower sensitivity to the second injection since the combustion is based on both the temperature and equivalence ratio distributions.

\section{CONCLUSIONS}

CFD simulations were performed for ethanol and PRF90 in an advanced LTC mode using a PFS-style split direct injection strategy. Ethanol and PRF90 were injected at different fuel split fractions in order to investigate the effects of fuel split fraction on

\section{REFERENCES}

Ansari, E., Poorghasemi, K., Irdmousa, B. K., Shahbakhti, M., and Naber, J. (2016). Efficiency and Emissions Mapping of a Light Duty Diesel-Natural Gas Engine Operating in Conventional Diesel and RCCI Modes. SAE Technical Paper. the combustion process. The following conclusions can be drawn based on the results:

- For both ethanol and PRF90, a split injection strategy improves the controllability of the combustion process by reducing the peak pressure and heat release rate and elongating combustion. This is due to the enhanced level of thermal and equivalence ratio stratifications.

- Increasing the split fraction of fuel in the late injection decreases the peak heat release rate and increases the burn duration by increasing the mixture stratification.

- Ethanol is more effective at reducing the peak heat release rate and increasing the burn duration than PRF90 due to its higher heat of vaporization and reduced $\phi$-sensitivity. When the $60-$ $40 \%$ split DI method is used, the burn duration increased by $118 \%$ for ethanol and $91.6 \%$ for PRF90.

- The temperature, equivalence ratio, and $\mathrm{OH}$ mass fraction of the early DI case is fairly homogenous; while for 60$40 \%$ split DI case, these distributions become very stratified. The late direct injection of fuel stratifies the mixture's equivalence ratio and stratifies the temperature distribution due to the evaporative cooling of the spray. The stratified equivalence ratio and temperature result is a staged, sequential autoignition and provides a mechanism to reduce the peak heat release rate.

- For ethanol, the $\mathrm{OH}$ mass fraction distribution is identical to the temperature distribution. However, for PRF90, the $\mathrm{OH}$ mass fraction distribution is affected by bot the temperature distribution and the equivalence ratio distribution, but these two distributions are coupled and compete with each other.

More work is required to understand how boosting effects the $\phi$ sensitivity for the primary reference fuel blend and how that in turn affects the combustion sequence.

\section{AUTHOR CONTRIBUTIONS}

MR is the corresponding author. She has performed various CFD simulations to study the effect of use of biofuel in advanced combustion. AS is the co-author. He has contributed in setting up the CFD model. BL and SM are the PI of the project. They have advised MR and AS in conducting their work.

\section{ACKNOWLEDGMENTS}

The authors would like to acknowledge the financial support of the Empire State Development under the NYSTAR HPC-NY program. Additionally, the authors would like to acknowledge the computational resources provided by the Institute for Advanced Computational Science (IACS) at Stony Brook University. 
Babajimopoulos, A., Assanis, D., Flowers, D., Aceves, S., and Hessel, R. (2005). A fully coupled computational fluid dynamics and multi-zone model with detailed chemical kinetics for the simulation of premixed charge compression ignition engines. Int. J. Eng. Res. 6, 497-512. doi: 10.1243/146808705X 30503

Beale, J. C., and Reitz, R. D. (1999). Modeling spray atomization with the KelvinHelmholtz/Rayleigh-Taylor hybrid model. Atomizat. Sprays 9, 623-650.

Berntsson, A. W., and Denbratt, I. (2007). HCCI Combustion Using Charge Stratification for Combustion Control. SAE Technical Paper.

Chiang, C., Raju, M., and Sirignano, W. (1992). Numerical analysis of convecting, vaporizing fuel droplet with variable properties. Int. J. Heat Mass Trans. 35, 1307-1324. doi: 10.1016/0017-9310(92)90186-V

Dec, J. E., Yang, Y., and Dronniou, N. (2011). Boosted HCCI-Controlling PressureRise Rates for Performance Improvements Using Partial Fuel Stratification with Conventional Gasoline. Livermore, CA: Sandia National Laboratories (SNLCA).

Flynn, P. F., Hunter, G. L., Zur Loye, A. O., Akinyemi, O. C., Durrett, R. P., Moore, G. A., et al. (2001). Premixed Charge Compression Ignition Engine with Optimal Combustion Control. Washington, DC: U.S. Patent and Trademark Office.

Han, Z., and Reitz, R. D. (1995). Turbulence modeling of internal combustion engines using RNG $\kappa-\varepsilon$ models. Combust. Sci. Technol. 106, 267-295. doi: 10.1080/00102209508907782

Johnson, D. R., Heltzel, R., Nix, A. C., Clark, N., and Darzi, M. (2017). Greenhouse gas emissions and fuel efficiency of in-use high horsepower diesel, dual fuel, and natural gas engines for unconventional well development. Appl. Energy 206, 739-750. doi: 10.1016/j.apenergy.2017.08.234

Kodavasal, J., Kolodziej, C. P., Ciatti, S. A., and Som, S. (2015). Computational fluid dynamics simulation of gasoline compression ignition. J Energ. y Resour. Technol. 137:032212. doi: 10.1115/1.4029963

Kodavasal, J., Kolodziej, C., Ciatti, S., and Som, S. (2014). CFD "Simulation of Gasoline Compression Ignition," in ASME 2014 Internal Combustion Engine Division Fall Technical Conference: American Society of Mechanical Engineers (Columbus, IN).

Kokjohn, S., Hanson, R., Splitter, D., and Reitz, R. (2011a). Fuel reactivity controlled compression ignition (RCCI): a pathway to controlled high-efficiency clean combustion. Int. J. Eng. Res. 12, 209-226. doi: $10.1177 / 1468087411401548$

Kokjohn, S., Hanson, R., Splitter, D., Kaddatz, J., and Reitz, R. D. (2011b). Fuel reactivity controlled compression ignition (RCCI) combustion in lightand heavy-duty engines. SAE Int. J. Eng. 4, 360-374. doi: 10.4271/2011-0 1-0357

Kolodziej, C., Kodavasal, J., Ciatti, S., Som, S., Shidore, N., and Delhom, J. (2015). Achieving Stable Engine Operation of Gasoline Compression Ignition Using 87 AKI Gasoline Down to Idle. SAE Technical Paper.

Kook, S., and Bae, C. (2004). Combustion Control Using Two-Stage Diesel Fuel Injection in a Single-Cylinder PCCI Engine. SAE Technical Paper.

Lawler, B., Hoffman, M., Filipi, Z., Güralp, O., and Najt, P. (2012). Development of a postprocessing methodology for studying thermal stratification in an HCCI engine. J. Eng. Gas Tur. Power 134:102801. doi: 10.1115/1.4007010

Lawler, B., Joshi, S., Lacey, J., Guralp, O., Najt, P., and Filipi, Z. (2014a). "Understanding the effect of wall conditions and engine geometry on thermal stratification and HCCI combustion,"in Proceedings of the ASME Internal Combustion Engine Division Fall Technical Conference, ICEF2014-5687 (Columbus, IN).

Lawler, B., Lacey, J., Dronniou, N., Dernotte, J., Dec, J. E., Guralp, O., et al. (2014b). Refinement and Validation of the Thermal Stratification Analysis: a Post-Processing Methodology for Determining Temperature Distributions in an Experimental HCCI Engine. SAE Technical Paper.

Lawler, B., Mamalis, S., Joshi, S., Lacey, J., Guralp, O., Najt, P., et al. (2017a). Understanding the effect of operating conditions on thermal stratification and heat release in a homogeneous charge compression ignition engine. Appl. Ther. Eng. 112, 392-402. doi: 10.1016/j.applthermaleng.2016.10.056

Lawler, B., Splitter, D., Szybist, J., and Kaul, B. (2017b). Thermally stratified compression ignition: a new advanced low temperature combustion mode with load flexibility. Appl. Energy 189, 122-132. doi: 10.1016/j.apenergy.2016. 11.034

Liu, A. B., Mather, D., and Reitz, R. D. (1993). Modeling the Effects of Drop Drag and Breakup on Fuel Sprays. DTIC Document.
Liu, Y.-D., Jia, M., Xie, M.-Z., and Pang, B. (2012). Enhancement on a skeletal kinetic model for primary reference fuel oxidation by using a semidecoupling methodology. Energy Fuels 26, 7069-7083. doi: 10.1021/ef $301242 b$

Marinov, N. M. (1999). A detailed chemical kinetic model for high temperature ethanol oxidation. Int. J. Chem. Kinet. 31, 183-220. doi: 10.1002/(SICI)1097-4601(1999)31:3<183::AID-KIN3>3.0.CO;2-X

Mehl, M., Chen, J.-Y., Pitz, W. J., Sarathy, S. M., and Westbrook, C. K. (2011). An approach for formulating surrogates for gasoline with application toward a reduced surrogate mechanism for CFD engine modeling. Energy Fuels 25, 5215-5223. doi: 10.1021/ef201099y

Najt, P. M., and Foster, D. E. (1983). Compression-Ignited Homogeneous Charge Combustion. SAE Technical Paper.

Onishi, S., Jo, S. H., Shoda, K., Do Jo, P., and Kato, S. (1979). Active ThermoAtmosphere Combustion (ATAC)-A New Combustion Process for Internal Combustion Engines. SAE Technical Paper.

Rahimi Boldaji, M., Sofianopoulos, A., Mamalis, S., and Lawler, B. (2018a). Computational fluid dynamics investigations of the effect of water injection timing on thermal stratification and heat release in thermally stratified compression ignition combustion. Int. J. Eng. Res. doi: 10.1177/1468087418767451. [Epub ahead of print].

Rahimi Boldaji, M., Sofianopoulos, A., Mamalis, S., and Lawler, B. (2017). "CFD Simulations of the effect of water injection characteristics on TSCI: a new, loadflexible, advanced combustion concept," in ASME 2017 Internal Combustion Engine Division Fall Technical Conference: American Society of Mechanical Engineers (Seattle).

Rahimi Boldaji, M., Sofianopoulos, A., Mamalis, S., and Lawler, B. (2018b). Effects of Mass, Pressure, and Timing of Injection on the Efficiency and Emissions Characteristics of TSCI Combustion with Direct Water Injection. SAE Technical Paper.

Reitz, R. D., and Bracco, F. (1986). Mechanisms of breakup of round liquid jets. Encycl. Fluid Mech. 3, 233-249.

Richards, K., Senecal, P., and Pomraning, E. (2014). Converge (v2. 2.0). Madison, WI: Theory Manual, Convergent Science.

Schmidt, D. P., and Rutland, C. (2000). A new droplet collision algorithm. J. Comput. Phys. 164, 62-80. doi: 10.1006/jcph.2000.6568

Sellnau, M., Sinnamon, J., Hoyer, K., and Husted, H. (2011). Gasoline direct injection compression ignition (GDCI)-diesel-like efficiency with low $\mathrm{CO}_{2}$ emissions. SAE Int. J. Eng. 4, 2010-2022. doi: 10.4271/2011-01-1386

Senecal, P., Pomraning, E., Richards, K., Briggs, T., Choi, C., McDavid, R., et al. (2003). Multi-Dimensional Modeling of direct-Injection Diesel Spray Liquid Length and Flame Lift-off Length Using CFD and Parallel Detailed Chemistry. SAE Technical Paper.

Shahsavan, M., and Mack, J. H. (2018). Numerical study of a boosted HCCI engine fueled with n-butanol and isobutanol. Energ. y Conver. Manag. e157, 28-40. doi: 10.1016/j.enconman.2017.11.063

Sjöberg, M., and Dec, J. E. (2006). Smoothing HCCI Heat-Release Rates Using Partial Fuel Stratification with Two-Stage Ignition Fuels. SAE Technical Paper.

Sjoberg, M., and Dec, J. E. (2011). Smoothing HCCI heat release with vaporizationcooling-induced thermal stratification using ethanol. SAE Int. J. Fuels Lubr. 5 , 7-27. doi: 10.4271/2011-01-1760

Sofianopoulos, A., Rahimi Boldaji, M., Lawler, B., and Mamalis, S. (2018). Application of Large Eddy Simulations to Premixed Low Temperature Combustion Engines. SAE Technical Paper.

Sofianopoulos, A., Zhou, Y., Lawler, B., and Mamalis, S. (2017). Gas exchange processes of a small HCCI free piston engine-A computational study. Appl. Ther. Eng. 127, 1582-1597. doi: 10.1016/j.applthermaleng.2017. 08.089

Splitter, D., Hanson, R., Kokjohn, S., and Reitz, R. D. (2011). Reactivity Controlled Compression Ignition (RCCI) Heavy-Duty Engine Operation at Mid-and HighLoads with Conventional and Alternative Fuels. SAE Technical Paper.

Su, T., Patterson, M., Reitz, R. D., and Farrell, P. (1996). Experimental and Numerical Studies of High Pressure Multiple Injection Sprays. SAE Technical Paper.

Tsolakis, A., and Megaritis, A. (2005). Partially premixed charge compression ignition engine with on-board $\mathrm{H}_{2}$ production by exhaust gas fuel reforming of diesel and biodiesel. Int. J. Hydrogen Energ. y 30, 731-745. doi: 10.1016/j.ijhydene.2004.06.013 
Wolk, B., Chen, J.-Y., and Dec, J. E. (2015). Computational study of the pressure dependence of sequential auto-ignition for partial fuel stratification with gasoline. Proc. Combustion Inst. 35, 2993-3000. doi: 10.1016/j.proci.2014.05.023

Yakhot, V., and Orszag, S. A. (1986). Renormalization group analysis of turbulence. I. Basic theory. J. Sci. Comput. 1, 3-51. doi: 10.1007/BF010 61452

Yang, Y., Dec, J. E., Dronniou, N., Sjöberg, M., and Cannella, W. (2011). Partial fuel stratification to control HCCI heat release rates: fuel composition and other factors affecting pre-ignition reactions of two-stage ignition fuels. SAE Int. J. Eng. 4, 1903-1920. doi: 10.4271/2011-01-1359
Conflict of Interest Statement: The authors declare that the research was conducted in the absence of any commercial or financial relationships that could be construed as a potential conflict of interest.

Copyright $\odot 2018$ Rahimi Boldaji, Sofianopoulos, Mamalis and Lawler. This is an open-access article distributed under the terms of the Creative Commons Attribution License (CC BY). The use, distribution or reproduction in other forums is permitted, provided the original author(s) and the copyright owner(s) are credited and that the original publication in this journal is cited, in accordance with accepted academic practice. No use, distribution or reproduction is permitted which does not comply with these terms. 